\title{
INTERRELATIONSHIP BETWEEN RADIOLOGIC FINDINGS AND PROGNOSIS OF EPILEPSY IN CHILDREN WITH NEUROCYSTICERCOSIS
}

\author{
Lisiane Seguti Ferreira', Verônica A. Zanardi , Li Min Li', Marilisa M. Guerreiro
}

\begin{abstract}
Introduction: Epileptic manifestations of Neurocysticercosis (NC) appear to depend on number and localization of the cysts. The objective of this study was to investigate the relationship between CT findings, number of parasites and the evolutive stage of the cysts, and the prognosis of epilepsy in children with NC. Method: We studied 28 patients with the parenchymal form of NC, considering: epilepsy duration; seizure frequency before and after AED treatment; seizure control; number of AED and recurrence after AED withdrawal. Clinical information was crossed with the number of lesions and disease activity in univariate comparison. Results: The analysis of the clinical data in relation to the number of lesions and disease activity showed no statistical difference among the variables $(p>0.05)$. Conclusion: We conclude that the course of epilepsy due to NC in childhood cannot be based exclusively on the number or stage of the parasites.
\end{abstract}

KEY WORDS: neurocysticercosis, childhood epilepsy, radiology, prognosis.

\begin{abstract}
Interrelação entre achados radiológicos e o prognóstico da epilepsia em crianças com neurocisticercose
RESUMO - Introdução: As manifestações epilépticas da neurocisticercose (NC) parecem depender do número e localização das lesões. 0 objetivo desse estudo foi investigar a relação entre os achados de CT, número de parasitas e estágio evolutivo dos cistos, com o prognóstico da epilepsia em crianças. Método: Nós estudamos 28 pacientes com a forma parenquimatosa da NC, considerando: duração da epilepsia; freqüência de crises antes e após o tratamento com DAE; aquisição de controle; número de drogas e recorrência. Esses aspectos foram correlacionados com o número de lesões e atividade da doença em análise estatística univariada. Resultados: A análise dos dados clínicos em relação ao número de lesões e atividade da doença não revelou diferenças estatisticamente significativas $(p>0,05)$. Conclusão: Concluímos que o curso da epilepsia por NC na infância não pode se basear exclusivamente no número ou estágio dos parasitas.
\end{abstract}

PALAVRAS-CHAVE: neurocisticercose, prognóstico, epilepsia na infância, radiologia.

Neurocysticercosis (NC) is a common health problem in developing countries. It affects patients of all ages and it is endemic in adults as well as among children in Latin America ${ }^{1-3}$. Epilepsy is the most important clinical manifestation. It occurs in $70-90 \%$ of all children with the parenchymal form of the disease, usually being its primary presentation ${ }^{4,5}$ the pathophysiology of the seizures due to NC is not completely understood yet. In active and transitional forms, seizures may be the consequence of compression or inflammatory reaction. In inactive form, perilesional gliosis is probably the cause of the seizures. Chronic inflammatory reaction sometimes takes several years to disappear and it may have an important role in the pathophysiology of focal epilepsy in
$N C^{6,7}$. Epileptic manifestations appear to depend on number and localization of the cysts ${ }^{8}$. Nevertheless, some studies have not shown any difference both in seizure frequency and in clinical or electroencephalographic characteristics in patients with a single lesion compared to those with multiple lesions 9,10 .

The objective of this study was to investigate the relationship between $\mathrm{CT}$ findings, number of parasites and the evolutive stage of the cysts, and the prognosis of epilepsy in children with NC.

\section{METHOD}

This was a retrospective study. We selected all patients with less than 16 years with probable or definitive diagnosis for NC according to Del Bruto et al. ${ }^{11}$. Forty-one pa-

Departamentos de Neurologia' e Radiologia², Universidade Estadual de Campinas (UNICAMP), Campinas SP, Brasil. Dr. Seguti received a scholarship from FAPESP.

Received 7 June 2001, received in final form 17 September 2001. Accepted 2 October 2001.

Dra. Marilisa M. Guerreiro - Departamento de Neurologia FCM / UNICAMP - Caixa Postal 6111 - $13083-970$ Campinas SP - Brasil. FAX: 193871 6715.E-mail:mmg@fcm.unicamp.br 
tients with NC were followed at the Pediatric Epilepsy Outpatient Clinic at the University of Campinas from January 1983 to January 1999. Five patients had a single seizure with follow-up of at least 12 months. Eight patients had the encephalitic form of NC. These 13 patients were excluded because single seizure is not epilepsy, and the encephalitic form is a more severe presentation of NC with a tendency for permanent neurological sequelae and severe epileptic condition than the one habitually found in patients with epilepsy resulting from NC.

We obtained all information from the remaining 28 patients on revision of their medical records, complemented with direct interview with patients and guardians whenever possible. A semi-structured protocol was filled in for every patient, considering: epilepsy duration (this was defined as the period between the first seizure up to the moment that antiepileptic drugs (AED) were withdrawn or until the last appointment for patients with persistent seizures, regardless of any remission period during the follow-up); seizure frequency before $A E D$ treatment was classified according to the total number of seizures quantified as: $A<10, B=10$ to $50, C>50$; seizure frequency after $A E D$ introduction (same classification as above) ; seizure control was defined as one year without having seizures; number of AED to obtain seizure control; recurrence after AED withdrawal (the policy of AED withdrawal was carried out after two years of seizure-freedom).

All 28 patients had computerized tomography scan (CT) at the time of the diagnosis in our center. All exams were revised by one of us (VAZ), a neuroradiologist with experience with NC. Lesions were counted and classified into three groups: five or less, between six and 10, and more than 10. Patients with a single calcification were excluded from this research. The disease activity was classified as active (appears on CT as hipodense cyst without enhancement), transitional (there is a ring or nodular contrast enhancement), and inactive (calcified lesions on CT) based on the viability of the parasite as proposed by Carpio et al. ${ }^{12}$. When lesions in different stages were found in the same patient, they were classified according to the most active lesion detected.
The clinical information listed above was crossed with the number of lesions and disease activity in univariate comparison using Kruskal-Wallis with post hoc pairwise comparison or Fisher exact test, and significance was assumed when $p<0.05$.

\section{RESULTS}

Twenty-eight patients (16 girls, mean age $=7.2$ years, mean follow-up of 64.5 months) had parenchymal form of NC and normal neurological examination and were the subjects of this study.

Concerning the evolutive stage of the parasite, 17 patients were at inactive phase, six at transitional phase and five children had active lesions on CT. Regarding number of lesions, 18 patients had five or less than five lesions, four had between six and 10 lesions, and six had more than 10 cysts.

The statistical analysis of clinical data in relation to the number of lesions and disease activity showed the following.

Epilepsy duration: mean duration of epilepsy was 7.2 years (range from 2.3 to 14.1 years). We did not find any statistical difference when we compared mean scores of epilepsy duration with stage (KruskalWallis test $p=0.20$ ) and number of lesions (KruskalWallis test $p=0.18$ ). Multiple cysts, regardless of stage, did not influence epilepsy duration and had the same behavior as a few lesions.

Seizure frequency: 12 patients had less than 10 seizures, 10 children had seizures between 10 and 50 , and six had more than 50 seizures. We did not find statistical difference when we compared in univaried analysis seizure frequency with stage and number of lesions (Table 1).

Seizure frequency after AED treatment: 15 patients had less than 10 seizures, nine had seizures between 10 and 50, and four had more than 50 seizures. There was no statistical difference comparing

Table 1. Seizure frequency.

\begin{tabular}{|c|c|c|c|c|c|c|}
\hline \multirow[b]{2}{*}{ Seizure frequency } & \multicolumn{3}{|c|}{ Number of lesions } & \multicolumn{3}{|c|}{ Disease activity } \\
\hline & $\leq 5$ & $5-10$ & $>10$ & Active & Inactive & Transitional \\
\hline \multirow[t]{2}{*}{$A(<10)$} & 10 & 1 & 1 & 1 & 7 & 4 \\
\hline & $35.7 \%$ & $3.5 \%$ & $3.5 \%$ & $3.5 \%$ & $25 \%$ & $14.3 \%$ \\
\hline \multirow[t]{2}{*}{$B(10-50)$} & 5 & 2 & 3 & 3 & 5 & 2 \\
\hline & $17.9 \%$ & $7.1 \%$ & $10.7 \%$ & $10.7 \%$ & $18 \%$ & $7.1 \%$ \\
\hline \multirow[t]{2}{*}{$C(>50)$} & 3 & 1 & 2 & 1 & 5 & 0 \\
\hline & $10.7 \%$ & $3.5 \%$ & $7.1 \%$ & $3.5 \%$ & $18 \%$ & \\
\hline \multicolumn{4}{|c|}{ Seizure frequency and number of lesions } & Fisher's exact & \multicolumn{2}{|c|}{ p 0.43} \\
\hline \multicolumn{4}{|c|}{ Seizure frequency and disease activity } & Fisher's exact & \multicolumn{2}{|c|}{ p 0.42} \\
\hline
\end{tabular}


Table 2. Seizure frequency after AED introduction.

\begin{tabular}{cccccccc}
\hline & \multicolumn{3}{c}{ Number of lesions } & & \multicolumn{3}{c}{ Disease activity } \\
\cline { 2 - 4 } \cline { 7 - 8 } Seizure frequency & 5 & $5-10$ & $>10$ & & Active & Inactive & Transitional \\
\hline A $<10$ & 12 & 2 & 1 & & 1 & 9 & 5 \\
& $42.9 \%$ & $7.1 \%$ & $3.6 \%$ & & $3.6 \%$ & $32.1 \%$ & $17.9 \%$ \\
B $10-50$ & 4 & 1 & 4 & & 3 & 5 & 1 \\
& $14.3 \%$ & $3.6 \%$ & $14.3 \%$ & & $10.7 \%$ & $17.9 \%$ & $3.6 \%$ \\
C $>50$ & 2 & 1 & 1 & & 1 & 3 & 0 \\
\hline Seizure frequency after AED and number of lesions & $7.1 \%$ & $3.6 \%$ & $3.6 \%$ & & $3.6 \%$ & $10.7 \%$ & \\
Seizure frequency after AED and disease activity & & & & Fisher's exact test & $\mathrm{p} 0.17$ \\
\hline
\end{tabular}

Table 3. Number of AEDs.

\begin{tabular}{|c|c|c|c|c|c|c|}
\hline \multirow[b]{2}{*}{ Number of drugs } & \multicolumn{3}{|c|}{ Number of lesions } & \multicolumn{3}{|c|}{ Disease activity } \\
\hline & $\leq 5$ & $5-10$ & $>10$ & Active & Inactive & Transitional \\
\hline \multirow[t]{2}{*}{1} & 8 & 1 & 0 & 1 & 7 & 1 \\
\hline & $28.6 \%$ & $3.6 \%$ & & $3.6 \%$ & $25 \%$ & $3.6 \%$ \\
\hline \multirow[t]{2}{*}{2} & 6 & 0 & 4 & 2 & 4 & 4 \\
\hline & $21.4 \%$ & & $14.3 \%$ & $7.1 \%$ & $14.3 \%$ & $14.3 \%$ \\
\hline \multirow[t]{2}{*}{$\geq 3$} & 4 & 3 & 2 & 2 & 6 & 1 \\
\hline & $14.3 \%$ & $10.7 \%$ & $7.1 \%$ & $7.1 \%$ & $21.4 \%$ & $3.6 \%$ \\
\hline \multicolumn{4}{|c|}{ Number of AED and number of lesions } & Fisher's exact & \multicolumn{2}{|c|}{ p 0.06} \\
\hline \multicolumn{4}{|c|}{ Number of AED and disease activity } & Fisher's Exact & \multicolumn{2}{|c|}{ p 0.52} \\
\hline
\end{tabular}

Table 4. Seizure control.

\begin{tabular}{|c|c|c|c|c|c|c|}
\hline \multirow[b]{2}{*}{ Seizure control } & \multicolumn{3}{|c|}{ Number of lesions } & \multicolumn{3}{|c|}{ Disease activity } \\
\hline & $\leq 5$ & 5-10 & $>10$ & Active & Inactive & Transitional \\
\hline Yes & 17 & 3 & 4 & 3 & 15 & 6 \\
\hline $\mathrm{n}=24$ & $60.7 \%$ & $10.7 \%$ & $14.3 \%$ & $10.7 \%$ & $53.6 \%$ & $21.4 \%$ \\
\hline No & 1 & 1 & 2 & 2 & 2 & 0 \\
\hline $\mathrm{n}=4$ & $3.6 \%$ & $3.6 \%$ & $7.1 \%$ & $7.1 \%$ & $7.1 \%$ & 0 \\
\hline \multicolumn{4}{|c|}{ Control seizure and number of lesions } & Fisher's exact & \multicolumn{2}{|c|}{ p 0.16} \\
\hline \multicolumn{3}{|c|}{ Control seizure and disease activity } & & Fisher's exact & \multicolumn{2}{|c|}{ p 0.40} \\
\hline
\end{tabular}

in univaried analysis seizure frequency after AED with stage and number of lesions (Table 2).

Number of AED: nine patients received only one AED during their treatment, 10 received two AED, and nine received three or more AED, either isolated or in association. There was no statistical difference comparing number of AED with stage and number of lesions (Table 3).

Seizure control: 24 patients obtained control of their epilepsy. The mean time to obtain control was 16.1 months. We did not find any difference when we compared seizure control with the stage and number of lesions (Table 4).

Recurrence: it occurred in 13 out of 24 evaluated patients. The mean time to seizure recurrence was 21.4 months, ranging from one to 48 months. There was no statistical difference when comparing recurrence with the stage and number of lesions (Table 5). 
Table 5. Recurrence.

\begin{tabular}{cccccccc}
\hline & \multicolumn{3}{c}{ Number of lesions } & & \multicolumn{3}{c}{ Disease activity } \\
\cline { 2 - 4 } Recurrence & 55 & $5-10$ & $>10$ & & Active & Inactive & Transitional \\
\hline Yes & 7 & 2 & 4 & & 1 & 10 & 2 \\
$\mathrm{n}=13$ & $29.1 \%$ & $8.3 \%$ & $16.7 \%$ & & $4.2 \%$ & $41.7 \%$ & $8.3 \%$ \\
No & 10 & 1 & 0 & & 2 & 5 & 4 \\
$\mathrm{n}=11$ & $41.7 \%$ & $4.2 \%$ & & $8.3 \%$ & $20.8 \%$ & $16.7 \%$ \\
\hline & Recurrence and number of lesions & & Fisher's exact test & & $\mathrm{p} \mathrm{0.08}$ \\
Recurrence and disease activity & & Fisher's exact test & & $\mathrm{p} \mathrm{0.40}$ \\
\hline
\end{tabular}

\section{DISCUSSION}

Neuroimaging has attained enormous progress during last decade. $\mathrm{CT}$ is very helpful in NC because it is a safe, precise and noninvasive method with more than $95 \%$ accuracy to define number, localization and evolutive stages of the parasites, especially in the parenchymal form of the disease. In developing countries where MRI machines are not always available, and considering the fact that calcifications are the main radiologic finding in NC, CT is still the most performed and useful examination ${ }^{13-16}$.

In this study, we tried to correlate CT findings (number and evolutive stages of lesions) with prognostic factors such as epilepsy duration, seizure frequency before and after AED introduction, number of AED, seizure control and seizure recurrence. In univaried analysis, we did not find any correlation among them. When isolated, neither number of parasites nor their stages are predictive factors of outcome. In this series, we observed seizure-free patients with multiple lesions in contrast to patients with refractory epilepsy with few lesions.

One limitation of our research is the low number of patients, which is due to the rigid inclusion criteria. However, out of 12 analyzed factors, only two showed borderline findings: number of lesions with recurrence $(p=0.08)$ and number of lesions with number of $A E D(p=0.06)$. If number of patients were higher, there would be a chance that statistical analysis could show different data of the two variables described above. Some authors found that patients with calcified lesions in large number have a worse prognosis, while other authors have different point of view ${ }^{9,17,18}$.

The poor understanding of the pathophysiology of the seizures due to NC parallels difficulties in explaining the variability of clinical manifestations $s^{7,19}$. Particularly in childhood, presentation may vary from "benign" to severe epileptic syndromes, such as Lennox-Gastaut syndrome ${ }^{10,20,21}$. Some factors that may contribute to explain this variability are: spontaneous resolution of the lesions; persistence of perilesional edema around calcified lesions; unpredictable evolution of the parasite that allows the coexistence of different forms in the same subject; the immune response of the host; and, the environment in which the child lives that may be responsible for new infestations ${ }^{15,22-25}$.

The severity of clinical manifestation has also been correlated to HLA antigens in the surface of the parasites, which suggests a genetic influence in the presentation of NC. Del Bruto 25 found higher rates of HLA 28 in patients with NC when compared to controls. Another antigen, DQW2, may be related to the resistance of the disease. Therefore, an individual predisposition to develop parenchymal NC is likely to occur and could in part explain the variability of the clinical expression.

We conclude that the course of epilepsy due to $\mathrm{NC}$ in childhood cannot be based exclusively on the number or stage of the parasites. Patients with multiple lesions will not necessarily present more seizures or need more drugs than the others. Intrinsic characteristics of the parasites as well as immunegenetic aspects may play important role in the explanation of the pleomorphic and unpredictable course of the clinical picture.

Acknowledgements - The authors thank Mrs. Cleide Moreira Silva for statistical support.

\section{REFERENCES}

1. Román GI. Neuroepidemiologia de la cisticercosis. In Guzmán TAA (ed). Cisticercosis del sistema nervoso. Guayaquil: Offset Abad, 1999:21-29.

2. Agapejev S. Epidemiology of neurocysticercosis in Brasil. Rev Inst Med Trop São Paulo 1996;38:207-216.

3. White AC Jr. Neurocysticercosis: a common cause of neurological disease worldwide. Clin Infect Dis 1997;24:101-115. 
4. Manreza MLG, Diament A. Cisticercosis pediátrica en Sudamérica. In San Esteban JE, Flisser A, Astiazarán, AG (eds). Neurocisticercosis en la infancia. Mexico: Grupo Editorial Miguel Ángel Porrúa, 1997:39-52.

5. Kalra V, Sethi A . Childhood neurocysticercosis: epidemiology, diagnosis and course. Acta Paediatr Jpn 1992;34:365-370

6. Carpio A, Escobar A, Hauser WA. Cysticercosis and epilepsy: a critical review. Epilepsia 1998;39:1025-1040.

7. Bittencourt PRM, Adamolekum B, Bharucha, et al. Epilepsy in tropics: II. Clinical presentations, pathophisiology, imunologic diagnosis, economics, and therapy. Epilepsia 1996;37:1128-1137.

8. Sotelo J, Del Bruto OH. Brain cysticercosis: review article. Arch Med Res 2000;31:3-14.

9. Monteiro L, Nunes B, Mendonça D. Spectrum of epilepsy in neurocysticercosis: a long term follow up of 143 patients. Acta Neurol Scand 1995;92:33-40.

10. Cukiert A, Puglia P, Scapolan HB, Vilela MM, Marino RJ. Congruence of the topography of intracranial calcifications and epileptic foci. Arq Neuropsiquiatr 1994; 52:289-293.

11. Del Bruto OH, Wadia NH, Dumas M, Cruz M, Tsang VCW, Schantz PM. Proposal of diagnostic criteria for human cysticecosis and neurocysticercosis. J Neurol Sci 1996;142:1-6.

12. Carpio A, Marcelo P, Santillan F, Alfonso E. A proposal for classification of neurocysticercosis. Can J Neurol Sci 1994;21:43-47.

13. Daras M, Tuckman AJ, Strobos RJ. Computed tomography in adultonset epileptic seizures in a city hospital population. Epilepsia 1987; 28:519-522.

14. Minguetti G, Ferreira MVC. Computed tomography in neurocysticercosis. J Neurol Neurosurg Psychiatry 1983;46:936-942.
15. Garcia MR, Astiazarán AG, Franco FR. Neurocysticercosis in children: clinical experience in 122 patients. Chid's Nerv Syst 1997;13:608-612.

16. Guerreiro MM, Facure NO, Guerreiro CAM. Aspectos da tomografia computadorizada craniana na neurocisticercose na infância. Arq Neuropsiquiatr 1989;47: 153-158.

17. Del Bruto OH. Prognostic factors for seizure recurrence after withdrawal of antiepileptic drugs in patients with neurocysticercosis. Neurology 1994;44:1706-1709.

18. Del Bruto OH. Neurocisticercosis en niños: análisis clínico, radiológico y factores prognósticos en 54 pacientes. Rev Neurol 1997;25:1681-1684.

19. Manreza MLG. Epilepsia e neurocisticercose. In Guerreiro CAM (ed). Epilepsia. São Paulo: Lemos Editorial, 2000:255-264.

20. Sakamoto AC, Bustamante VCT, Garzon E, et al. Cysticercosis and epilepsy. In Kotagal P, Luders HO (eds). The epilepsies: etiologies and prevention. New York: Academic Press, 1999:275-282.

21. Agapejev S, Padula NAMR, Morales NMO, Lima MMF. Neurocisticercose e síndrome de Lennox-Gastaut. Arq Neuropsiquiatr 2000;58: 538-547.

22. Nash TE, Patronas NJ. Edema associated with lesions in neurocysticercosis. Neurology 1999;53:777-781.

23. Miller B, Grinnell V, Goldberg MA, Heiner D. Spontaneous radiographic disappearance of cerebral cysticercosis: three cases. Neurology 1983;33: 1377-1379.

24. White AC Jr. Neurocysticercosis: updates on epidemiology, pathogenesis, diagnosis and management. Annu Rev Med 2000;5:187-206.

25. Del Brutto OH, Granados G, Talamas O, Sotelo J, Gorodesky C. Genetic pattern of the HLA system: HLA A, B, C, DR, and DQ antigens in mexican patients with parenchymal brain cysticercosis. Hum Biol $1991 ; 63: 85-93$ 